\title{
Guidelines for the prevention and management of Mycobacterium tuberculosis infection and disease in adult patients with chronic kidney disease
}

\author{
Prepared by members of the Guideline Group on behalf of the British Thoracic Society \\ Standards of Care Committee and Joint Tuberculosis Committee, Heather Milburn, ${ }^{1}$ \\ Neil Ashman, ${ }^{2}$ Peter Davies, ${ }^{3}$ Sarah Doffman, ${ }^{4}$ Francis Drobniewski, ${ }^{5}$ Saye Khoo, ${ }^{6}$ \\ Peter Ormerod, ${ }^{7}$ Marlies Ostermann, ${ }^{8}$ Catherine Snelson ${ }^{9}$
}

\begin{abstract}
${ }^{1}$ Chest Clinic, Guy's and St Thomas' NHS Foundation Trust, London UK

'Barts' and the London Renal Centre, London, UK

${ }^{3}$ Liverpool NHS Trust, Liverpool, UK

${ }^{4}$ Brighton General Hospital, Brighton, UK

'Barts' and the London, London, UK

${ }^{6}$ University of Liverpool, Liverpool, UK

${ }^{7}$ Royal Blackburn Hospital, Blackburn, UK

${ }^{8}$ Guy's Hospital, London, UK

${ }^{9}$ Princess Royal Hospital,

Telford, Birmingham, UK
\end{abstract}

\section{Correspondence to}

Dr H Milburn, Consultant Respiratory Physician

(Chairman), Chest Clinic, Guy's Hospital, St Thomas' Street, London SE1 9RT, UK; heather.milburn@gstt.nhs.uk

Received 14 December 2009 Accepted 24 January 2010

\begin{abstract}
Guidelines have been compiled by the Joint Tuberculosis Committee of the British Thoracic Society for the prevention and management of Mycobacterium tuberculosis infection and disease in patients with all grades of renal impairment.
\end{abstract}

Patients with renal disease are at increased risk of tuberculosis (TB). This is true for all patients with chronic kidney disease (CKD), but particularly so for those from ethnic minority groups who are both at increased risk of developing active TB disease and in whom the prevalence of CKD is also substantially higher. Despite this increased risk, there are few guidelines for the investigation and treatment of TB disease in CKD. ${ }^{1}$ Although there is broad agreement over drug treatment and its duration, there are differing views regarding dosing. There are no randomised controlled trials into outcomes in patients with advanced CKD, and little information specifically dealing with issues of immunosuppression and transplantation. The evidence to guide protocols for active case finding (screening) and treatment of latent disease is limited and there is variation in practice to approaches to prevent reactivation. Evidence consists of small prospective studies of haemodialysis clearance, pharmacokinetic studies of therapy in renal failure, retrospective observational data, case reports and expert opinion.

The objectives of these guidelines are to quantify the risks of developing active disease and to give advice where possible on the management of $\mathrm{TB}$ infection and disease in patients (1) with all stages of CKD (box 1); (2) on peritoneal dialysis and haemodialysis; and (3) with renal transplants. The risks of developing disease and the risks and benefits of treatment for latent TB infection are covered. These guidelines are intended to inform renal physicians and surgeons, respiratory physicians and infectious diseases physicians treating TB together with specialist nurses in those disciplines.

\section{SUMMARY OF KEY POINTS}

Evidence informing these guidelines (based on the revised SIGN grading systems, boxes 2 and 3 ) supports the following:

- Patients with chronic kidney disease (CKD), on dialysis and following transplantation are at significantly increased risk of tuberculosis (TB).
Box 1 Grades of renal impairment in chronic kidney disease (CKD)

Stage 1 CKD: Normal creatinine clearance and function but urinary tract abnormality, for example, polycystic kidney, structural abnormality.

Stage 2 CKD: Creatinine clearance $60-90 \mathrm{ml} / \mathrm{min}$ Stage 3 CKD: Creatinine clearance $30-60 \mathrm{ml} / \mathrm{min}$ Stage 4 CKD: Creatinine clearance $15-30 \mathrm{ml} / \mathrm{min}$ Stage 5 CKD: Creatinine clearance $<15 \mathrm{ml} / \mathrm{min}$ with or without dialysis.

\section{Box 2 Revised Scottish Intercollegiate} Guidelines Network (SIGN) grading system: grades of recommendation

A At least one meta-analysis, systematic review or randomised controlled trial (RCT) rated as $1++$ and directly applicable to the target population; or A systematic review of RCTs or a body of evidence consisting principally of studies rated as $1+$ directly applicable to the target population and demonstrating overall consistency of results. B A body of evidence including studies rated as $2++$ directly applicable to the target population and demonstrating overall consistency of results; or Extrapolated evidence from studies rated as $1++$ or $1+$.

C A body of evidence including studies rated as $2+$ directly applicable to the target population and demonstrating overall consistency of results; or Extrapolated evidence from studies rated as $2+$. D Evidence level 3 or 4; or Extrapolated evidence from studies rated as $2+$.

- Patients born overseas who have been in the UK for $<5$ years, those of African, Asian, South American or Eastern European ethnicity and anyone with a history of contact with smear positive pulmonary disease have an additional significantly increased risk of TB.

- Around $50 \%$ of patients with CKD have reduced skin test responsiveness to the tuberculin skin test; that is, freedom from TB cannot be inferred from a negative tuberculin skin test in a patient with CKD. 
Box 3 Revised Scottish Intercollegiate Guidelines

Network (SIGN) grading system: levels of evidence

$1++$ High-quality meta-analyses, systematic reviews of randomised controlled trials (RCTs) or RCTs with a very low risk of bias.

$1+$ Well-conducted meta-analyses, systematic reviews of RCTs or RCTs with a low risk of bias.

1- Meta-analyses, systematic reviews of RCTs or RCTs with a high risk of bias.

$2++$ High-quality systematic reviews of case-control or cohort studies. High-quality case-control or cohort studies with a very low risk of confounding, bias or chance and a high probability that the relationship is causal.

2+ Well-conducted case-control or cohort studies with a low risk of confounding, bias or chance and a moderate possibility that the relationship is causal.

2- Case-control or cohort studies with a high risk of confounding, bias or chance and a significant risk that the relationship is not causal.

3 Non-analytical studies (eg, case reports, case series).

4 Expert opinion.

There is little or no evidence at present to answer the following points:

- There is no evidence on when to screen for latent TB infection (LTBI) or which patients should receive chemoprophylaxis.

- Supporting evidence for methods of screening for LTBI is limited.

- There is inconsistency in published dosages, dose intervals and timing of doses for patients on dialysis.

\section{RECOMMENDATIONS}

1. All patients with chronic kidney disease (CKD) considered at risk for tuberculosis $(\mathrm{TB})$ should have a history of prior $\mathrm{TB}$ or $\mathrm{TB}$ contact sought, any history of prior TB treatment checked (including drugs taken and treatment duration), an appropriate clinical examination, a chest $\mathrm{x}$-ray and, if appropriate, an interferon gamma release assay (IGRA) test specific for Mycobacterium tuberculosis antigens (see text). (D)

2. Any patient with $\mathrm{CKD}$ with an abnormal chest $\mathrm{x}$-ray consistent with past $\mathrm{TB}$, or previous history of extrapulmonary TB but who has previously received adequate treatment should be monitored regularly and considered for referral to and assessment by a specialist with an interest in $T B$, either a thoracic or infectious diseases physician. (D)

3. Routine assessment of patients with CKD or those on haemodialysis or peritoneal dialysis with a tuberculin skin test (TST) or IGRA test is not recommended. Renal physicians may wish to assess individual patients at high risk of latent $\mathrm{TB}$ infection (LTBI) with an IGRA test (with or without a TST, a negative test being unhelpful) and discuss the results with a chest/infectious diseases specialist in TB. (D)

4. Patients on the waiting list for renal transplantation may be assessed with an IGRA test (with or without a TST, as above), giving the opportunity for chemoprophylaxis before transplantation. An individual risk assessment can be made (see below). In general, all black African and Asian patients born outside the UK should be screened and considered for chemoprophylaxis before or after transplantation. (D)

5. The decision on chemoprophylaxis regimen should be made by the thoracic or infectious disease physician after discussion with both the patient and renal team. (D)

6. In general, isoniazid and rifampicin can be used in normal doses in renal impairment, during dialysis and following transplantation (see below). (D)

7. For chemoprophylaxis, use 6 months of isoniazid $300 \mathrm{mg}$ daily plus pyridoxine $10-25 \mathrm{mg}$ daily, or isoniazid plus rifampicin (as Rifinah) plus pyridoxine for 3 months or rifampicin alone for 4-6 months. Any of these regimens is adequate for chemoprophylaxis. Long-term use of isoniazid is not recommended. (A)

8. There is no evidence to support chemoprophylaxis regimens of longer than 6 months for isoniazid alone, 3 months for isoniazid plus rifampicin, or 4-6 months for rifampicin alone. (A)

9. There is no evidence to support use of lower doses. These are inadequate for treatment of LTBI and lead to lower peak levels and possible development of drug resistance. (D)

10. If patients who have had chemoprophylaxis develop symptoms suggestive of clinical TB, they should be promptly and appropriately investigated. (A)

11. If active $T B$ is suspected, every effort should be made to isolate an organism for sensitivity testing. (B)

12. Patients with active pulmonary disease should be isolated, preferably in negative pressure facilities. (D)

13. All cases of TB should be notified to the proper officer, usually the local consultant in Communicable Disease Control. (A)

14. Close cooperation between renal physicians and specialists in the management of TB is strongly recommended. (D)

15. Active TB should be excluded in patients with $C K D$ by appropriate investigations in patients who have an abnormal chest x-ray or a history of prior pulmonary or extrapulmonary TB that has been either inadequately or not previously treated. Chemoprophylaxis should be given. (A)

16. TB should be considered in all patients with unexplained systemic or system-specific symptoms as extrapulmonary TB is common, particularly in patients on dialysis, with peritoneal TB being common in patients on chronic ambulatory peritoneal dialysis. (B)

17. Any patient with active $T B$, either pulmonary or nonpulmonary, should receive standard chemotherapy agents, albeit with dose interval modifications where appropriate (see text) and for standard duration as per the NICE guidelines. (A)

18. Peak and trough drug levels should be monitored, particularly for ethambutol and the aminoglycosides, especially if there is concern regarding over- and under-dosing. (D)

19. For patients with stages 4 and $5 \mathrm{CKD}$, dosing intervals should be increased to three times weekly for ethambutol, pyrazinamide and the aminoglycosides. (D)

20. For patients on haemodialysis, dosing intervals for ethambutol, pyrazinamide and the aminoglycosides should be increased to three times weekly to reduce the risk of drug accumulation and toxicity. (D)

21. Treatment can be given immediately after haemodialysis to avoid premature drug removal. With this strategy there is a possible risk of raised drug levels of ethambutol and pyrazinamide between dialysis sessions. Alternatively, treatment can be given $4-6 \mathrm{~h}$ before dialysis, increasing the possibility of premature drug removal but reducing possible ethambutol or pyrazinamide toxicity. The choice of strategy may be influenced by a need to ensure adherence (when post dialysis offers the 
opportunity for directly observed therapy), practical issues (post dialysis for morning shift patients) and expected pharmacokinetics or drug interactions. (D)

22. Rifampicin in particular can interact with immunosuppressive regimens, increasing the chance of graft rejection, and doses of mycophenolate mofetil, tacrolimus and ciclosporin may need adjustment. Corticosteroid doses should be doubled in patients receiving rifampicin. (B)

\section{INTRODUCTION}

\subsection{Structure of the recommendations}

The format follows that used for other BTS guidelines. At the beginning there is a summary of the abstracted bullet points from each section. The recommendations use the revised Scottish Intercollegiate Guidelines Network (SIGN) grading system available at http://www.sign.ac.uk/guidelines/fulltext/59/ section6.html (box 2). The primary source literature has been individually graded for its methodology (where appropriate) and the grading given alongside the reference using the revised SIGN levels of evidence (box 3 ).

\subsection{Methodology for the creation of the recommendations}

The initial systematic literature search (Medline, DataStar Web) was carried out by two members of the committee (CS and SD) using tuberculosis, renal/kidney failure, renal transplant 1970-2009 as search criteria. A paper-based exploration of the relevant literature was pursued from this core dataset. Only English language papers including all well formulated clinical case series were included. Abstracts were excluded.

After the appraisal of data, the guideline was initially drafted by HM with SD and PD, then discussed by the whole group, the evidence debated and redrafted several times. The draft was based where possible on any published evidence, but this was combined with clinical expertise where necessary and where no evidence was available. The manuscript was then placed on the BTS website for consultation by the membership. Following this, further amendments were made and the document reviewed by the TB Specialist Advisory Group, Joint Tuberculosis and Standard of Care Committees of the BTS. After final approval from these committees together with input from the Renal Association, the guidelines were submitted for peer review prior to publication.

\subsection{Suggested review date}

The Guidelines Committee suggest that the guidelines be reviewed in 3 years from date of publication.

\section{BACKGROUND}

\subsection{The need for recommendations}

Advanced CKD is associated with an acquired immunodeficiency state as a result of functional abnormalities of neutrophils, reduced $\mathrm{T}$ and $\mathrm{B}$ cell function and compromised monocyte and natural killer cell function. ${ }^{11} 12$ 25-Hydroxyvitamin D insufficiency, common in stages 3-5 CKD, may also have an important role through impaired monocyte function, reducing production of cathelicidin, a peptide capable of destroying Mycobacterium tuberculosis. ${ }^{13}$ The risk of developing $\mathrm{TB}$ is compounded further by associated comorbid conditions, immunosuppressive drugs and socioeconomic factors. ${ }^{14-16}$ According to the NICE guidelines, the relative risk (RR) for developing active TB is $10-25$ in patients with CKD or in those on haemodialysis and 37 for renal transplant recipients ${ }^{17}$ where the normal inflammatory response to infection is attenuated by immunosuppressive therapy.
In clinical practice, there are still conflicting data relating to early identification of patients at risk, optimal prophylaxis and best forms of treatment for those with latent tuberculosis infection (LTBI). The American Thoracic Society/Centre for Disease Control committee on LTBI recommends targeted tuberculin skin testing (TST) for all patients with CKD, including transplant recipients, ${ }^{18}$ and the Spanish Group for the Study of Infection in Transplant Recipients recommends TST as part of the evaluation of all potential candidates for solid organ transplantation. ${ }^{19}$ However, it is well known that this test lacks sensitivity, especially in patients on dialysis, with reported anergy rates of up to $50 \% .^{20-23}$ Immunosuppressants used as treatment for kidney disease and in transplantation (including prednisolone, azathioprine, cyclophosphamide, ciclosporin, tacrolimus or mycophenolate mofetil and newer monocloncal antibodies) interfere with the accuracy of the TST. ${ }^{24}$ Chemoprophylaxis for LTBI itself carries a small risk of adverse events in patients with normal renal function, particularly of druginduced hepatitis which increases with age and is occasionally fatal. There are no equivalent data for patients with CKD. It is also important to exclude active TB disease before chemoprophylaxis is given, particularly as single agent chemoprophylaxis given when active disease is present could lead to the development of drug resistance. ${ }^{25}$

Diagnosis of active TB is often delayed in patients with CKD as the clinical presentation may be uncharacteristic, especially in patients with extrapulmonary manifestations and non-specific symptoms. ${ }^{26}$ Finally, there is controversy about the optimal methods of delivering treatment for TB in patients with $\mathrm{CKD}$. Some important antituberculosis drugs are renally excreted and data on drug clearance during haemodialysis or peritoneal dialysis are scarce. These issues have led to many requests for advice.

\subsection{Background epidemiology}

Most information on the magnitude of the problem of TB in patients with $\mathrm{CKD}$, on dialysis or following renal transplantation comes from countries with a high background prevalence, but there is little information from the UK. In the UK, CKD is four times more common in Asians and black people than in white people, ${ }^{27}$ and it is in these former communities where $\mathrm{TB}$ is most prevalent. The incidence of $\mathrm{TB}$ in $\mathrm{CKD}$ in areas of high background prevalence is high, with a study of 1498 Chinese patients demonstrating a RR of $31.4 .^{28}$ Retrospective studies of patients on maintenance haemodialysis have, however, led to estimates of a 10-25-fold higher risk of developing TB compared with the general population. ${ }^{14-16} 29-31 \mathrm{~TB}$, particularly peritoneal disease, is also a problem in patients on chronic ambulatory peritoneal dialysis (CAPD), but studies are few and case rates difficult to determine. ${ }^{32} 33$ TB prevalence studies in renal transplant recipients give case rates ranging from 100 to 400 per 100000 in Northern Europe and North America. ${ }^{34-41}$ A single centre experience from Belgium suggested a post-transplant prevalence of $0.36 \% \quad(360 / 100000) .{ }^{42}$ In a review of 756 transplanted patients in Taiwan, the prevalence of TB was $3.8 \%$. ${ }^{43}$ Studies from the Indian subcontinent unsurprisingly suggest a much higher prevalence (5-14\%). ${ }^{44-47}$ Further studies show an increased risk of post-transplant TB with increased duration of pretransplant haemodialysis and number of post-transplant rejection episodes, ${ }^{48}$ and with the peak incidence of $\mathrm{TB}$ occurring after the first year following transplantation. ${ }^{49}$ Immunosuppression with tacrolimus or mycophenylate mofetil is, however, associated with the 
development of TB earlier in the post-transplant period and in younger patients. ${ }^{39}$

The 2006 NICE guidelines give an overall RR following renal transplantation of $37,{ }^{17}$ based on a small series from $1983 .{ }^{36}$ Refinements in immunosuppression, however, have led to marked reduction in rejection rates and a rise in infective complications. It is therefore likely that this risk has increased over time.

\section{DIAGNOSIS OF LATENT TB INFECTION}

It is beyond the scope of these guidelines to discuss the underlying mechanisms of LTBI, but the condition can be defined as infection with $M$ tuberculosis at some earlier time with viable organisms remaining in a dormant state. The diagnosis of LTBI is not straightforward, but most physicians would use evidence of previous primary infection on the chest x-ray, a large tuberculin response or evidence of immunity to TB-specific antigens. Patients born in areas of high endemnicity who have been in the UK for $<5$ years, those of African, Asian, South American or Eastern European ethnicity and anyone with a history of contact with smear-positive pulmonary disease have an additional significantly increased risk of LTBI or active disease. A full discussion of LTBI can be found elsewhere. ${ }^{50}$

\subsection{Timing of screening}

For patients with CKD, there is no evidence on when or how to screen for LTBI. Screening all patients with advanced CKD or even only those on haemodialysis or peritoneal dialysis would be time-consuming, expensive and unlikely to be cost-effective, but in order to give guidance on this issue, data on the rates of active TB in these groups need to be collected. Some patients are more at risk than others, for example, some ethnic minority groups and patients born abroad in areas of high prevalence (table 1) and those on immunosuppression or due to start immunosuppression for transplantation. The $\mathrm{RR}$ of developing $\mathrm{TB}$ in patients with CKD is assumed to be increased 20-fold compared with the normal population.

The risk of developing active TB following renal transplantation is particularly high, and screening may be beneficial for this group. The current practice in most renal units is to give prophylaxis to all at-risk transplant patients without assessment. A significant proportion of patients will be receiving prophylaxis without evidence of LTBI. Chemoprophylaxis could be offered to those with LTBI before transplantation, precluding the need for post-transplant prophylaxis. Whether or not a screening and treatment programme has benefit over universal post-transplant prophylaxis with isoniazid in those most at risk is unknown. There are advantages in screening before transplantation compared with after transplantation when immunosuppression may affect the assays used, and treating LTBI with rifampicin (which has potent interactions with immunosuppressive agents) offers a substantial risk to the allograft.

\subsection{Method of screening}

All patients with CKD, on haemodialysis or CAPD and prior to renal transplantation should have a chest $\mathrm{x}$-ray and abnormalities investigated. Most patients will have normal x-rays and the response to tuberculin or TB-specific antigens will be needed for screening for LTBI in appropriate patients. The TST is unreliable in patients with advanced CKD and in those on immunosuppressive agents. A positive test may be useful but a negative result cannot be assumed to be a true negative. The new inter-
Table 1 Annual risk of tuberculosis disease/100 000 in England and Wales

\begin{tabular}{|c|c|c|c|c|}
\hline \multicolumn{5}{|c|}{ (A) Effect of age (to the nearest whole number) } \\
\hline \multicolumn{2}{|c|}{ Age (years) } & \multicolumn{2}{|l|}{ White } & Black-African \\
\hline $0-14$ & & 1 & & 47 \\
\hline $15-34$ & & 2 & & 314 \\
\hline $35-54$ & & 4 & & 168 \\
\hline $55-74$ & & 7 & & 204 \\
\hline$>75$ & & 11 & & Not available \\
\hline \multicolumn{5}{|c|}{ (B) Effect of place of birth/duration in England and Wales } \\
\hline Age & $\begin{array}{l}\text { Place of } \\
\text { birth }\end{array}$ & $\begin{array}{l}\text { Years after } \\
\text { first entry }\end{array}$ & $\begin{array}{l}\text { All patient } \\
\text { rate }\end{array}$ & $\begin{array}{l}\text { ISC ethnic } \\
\text { rate }\end{array}$ \\
\hline \multirow[t]{2}{*}{$0-14$} & UK & & 3 & 21 \\
\hline & Abroad & & 31 & 88 \\
\hline $15+$ & UK & & 4 & 59 \\
\hline \multirow[t]{2}{*}{$15-34$} & Abroad & $0-4$ & 180 & 540 \\
\hline & & $\geq 5$ & 53 & 87 \\
\hline \multirow[t]{2}{*}{$35+$} & Abroad & $0-4$ & 146 & 593 \\
\hline & & $\geq 5$ & 39 & 108 \\
\hline
\end{tabular}

Population figures from the Office of National Statistics Labour Force Survey 2000 TB data from case reports to Enhanced TB Surveillance 2000 Health Protection Agency. How to use: If white and UK-born, use data from table 1A. If Indian subcontinent (ISC), use table 1B. If Black-African use, table 1A (similar data to table 1B not yet available). If either white non-UK born or other ethnic group, use All patient rate (table 1B). If in doubt or in special circumstances, consult local thoracic physician. Taken from reference 10 with permission. ISC, Indian subcontinent.

feron gamma release assay (IGRA) tests have not been fully evaluated in these groups of patients, although studies are ongoing and planned across Europe (Tuberculosis Network European Trials Group, TBNET). There are two commercially available tests, the T-SPOT.TB assay (Oxford Immunotec, UK) and the QuantiFERON-TB Gold (Cellestis, Australia). While the QuantiFERON test is technically easier to perform, recent evidence suggests that the T-SPOT is the more sensitive of the two tests, especially in immunosuppressed patients. ${ }^{51} \mathrm{~A}$ recent study compared the T-SPOT.TB with the TST and the opinions of an expert physician panel in 203 patients on haemodialysis exposed to infectious TB. The T-SPOT.TB correlated more closely with surrogate markers of LTBI (radiographic changes, previous history of $\mathrm{TB}$, born in a TB endemic country) than the TST, and with clinical judgement than with the TST. ${ }^{52}$ In a further study, both IGRA tests were compared with the TST in 100 patients on renal dialysis exposed to a case of sputum smear positive TB. Positive IGRA results were more closely associated with recent exposure than were positive TST results. ${ }^{53}$ Triverio and colleagues ${ }^{54}$ found the QuantiFERON test to be superior to the TST for detecting LTBI in 62 haemodialysis patients, but this study showed that both IGRA tests and the TST have important limitations. Another recent small study gave sensitivity, specificity and positive and negative predictive values of the QuantiFERON test for active TB disease in 32 patients with $\mathrm{CKD}$ as $100 \%, 62.1 \%, 8.3 \%$ and $100 \%$, respectively. ${ }^{55}$ The limited evidence available to date, however, suggests that IGRA tests may be more useful as a screening tool for LTBI in this patient group than the TST. These must, however, be interpreted in the light of radiographic changes, previous history of TB, foreign travel, ethnic and environmental background, as indeterminate assays are more likely in this population and there is scant evidence on negative predictive values of these tests in this patient group. The IGRA tests are not affected by previous BCG vaccination or infection with most environmental mycobacteria, but cannot distinguish between LTBI and active disease. 


\section{CHEMOPROPHYLAXIS}

There are three potential chemoprophylaxis regimens: isoniazid for 6 months $(6 \mathrm{H})$, rifampicin plus isoniazid for 3 months (3RH) or rifampicin alone for 4-6 months (4-6R). Rifampicin and pyrazinamide for 2 months ( $2 R Z$ ) was a regimen used in the USA $^{56}$ but it was associated with a very high rate of hepatitis (table 2), with a number of fatalities reported. ${ }^{57} 58$ Accordingly, the choice of regimen is between $6 \mathrm{H}$, which has a lower hepatitis rate, $3 \mathrm{RH}$ which may have advantages in terms of shorter duration and thus possibly better adherence (table 2) and also less risk of drug resistance developing if active disease is present, ${ }^{59}$ and $4-6 \mathrm{R}$ which also has the disadvantage of a single agent but was better tolerated than 9 months of isoniazid alone ${ }^{7}$ and can be used following contact with isoniazid-resistant disease.

There are few data on chemoprophylaxis specifically in patients with $\mathrm{CKD}$. One report of isoniazid prophylaxis for 1 year in 109 patients with CKD on haemodialysis showed reduced numbers developing TB with an RR of $0.4 .^{60}$ Significant hepatitis, however, developed in $16.7 \%$; most of these were either hepatitis B or C positive, emphasising the increased risk of treatment in those with known liver disease. One year of isoniazid prophylaxis following transplantation reduced the incidence of TB by about $50 \%{ }^{61-63}$

No chemoprophylaxis regimen is wholly effective; protective efficacies of $60-65 \%$ have been reported for $6 \mathrm{H}^{64}$ and of $50 \%$ for $3 \mathrm{RH} .{ }^{6}$ There is strong evidence that regimens longer than $6 \mathrm{H}$ have only very minimal additional advantage at the cost of an increase in the risk of hepatitis. ${ }^{64}$ Evidence is not yet available for $4-6 R$.

\section{RISKS OF TUBERCULOSIS AND OF DRUG-INDUCED HEPATITIS FROM CHEMOPROPHYLAXIS}

\subsection{Risks of TB}

The risk of developing active TB has been reported in earlier BTS guidelines and is reproduced here. ${ }^{10}$ The incidence of $\mathrm{TB}$ in the population of the UK varies markedly according to a number of factors ${ }^{65}{ }^{66}$ : age, ethnic group and, for those not born in the UK, the length of time since first entry. Where possible, data on the current annual risk of $\mathrm{TB}$ have been updated from those derived from continuous enhanced surveillance (table 1).

Calculation of the risk of TB is as follows:

- If white and UK-born, use table 1A.

- If Indian subcontinent (ISC), use table 1B.

- If black-African, use table 1A (similar data to table 1B not yet available).

- If either white non-UK born or other ethnic group (including black Caribbean), use 'all patient rate' in table 1B.

- If in doubt or in special circumstances, consult the lead clinician for TB, usually the local thoracic physician.

\subsection{Risks of drug-induced hepatitis from TB chemoprophylaxis}

The rates of drug-induced hepatitis from various TB chemoprophylaxis regimens have been given in earlier BTS guidelines. ${ }^{10}$ These were based on a database search (Medline and Embase) of the reported hepatotoxicity of antituberculosis chemoprophylaxis from 1966 to 2002 in adults. A further database search to 2009 has not altered the rates given in the earlier BTS guidelines ${ }^{10}$ and reproduced here, but the regimen of $4-6$ months of rifampicin has been included. Children were excluded as they have a very low rate of drug reactions, and studies in HIVpositive patients were also excluded because such individuals have a higher than normal drug reaction profile. ${ }^{67}$ The hepatitis rates for various regimens are shown in table 2 .

Only hepatitis sufficient to stop treatment (symptomatic) or grade 3 (alanine transferase (ALT) 5-20 times normal) or grade 4 (ALT >20 times normal) hepatitis is reported here, although the 1998 BTS Guidance on Chemotherapy and Management of TB recommended monitoring liver function weekly if levels of hepatic transaminases rose to twice normal. ${ }^{68}$ The current guidance does not apply to patients co-infected with HIV, hepatitis B or C.

\section{RECOMMENDATIONS FOR MANAGEMENT OF LTBI \\ 6.1 Assessment}

1. All patients with CKD considered at risk for TB should have any history of prior TB or TB contact sought, any history of prior TB treatment checked (including drugs

Table 2 Hepatic risks of chemoprophylaxis

\begin{tabular}{|c|c|c|c|c|}
\hline Reference & $\mathbf{N}$ & Hepatitis/100000* & $\%$ Completion & Comments \\
\hline \multicolumn{5}{|l|}{ Regimen $6 \mathrm{H}$} \\
\hline IUALTD $^{2}$ & 6965 & 480 & 78 & $65 \%$ protective efficacy (one death from $6 \mathrm{H}$ ) \\
\hline Jasmer $^{3}$ & 282 & 1000 & 59 & \\
\hline Nolan $^{4}$ & 11141 & 100 & - & $\begin{array}{l}\text { Female OR } 3.3(95 \% \mathrm{Cl} 0.87 \text { to } 12.45) \\
\text { White OR } 2.60(95 \% \mathrm{Cl} 0.75 \text { to } 8.95) \\
\text { Increase with age } \chi^{2} 5.22(\mathrm{p}=0.02)\end{array}$ \\
\hline Bailey $^{5}$ & 427 & 1170 & & \\
\hline Weighted average & 18815 & 278 & & \\
\hline \multicolumn{5}{|l|}{ Regimen 3RH } \\
\hline HK TB Service ${ }^{6}$ & 170 & 1766 & - & $50 \%$ protective efficacy in silicosis \\
\hline \multicolumn{5}{|l|}{ Regimen 4-6R } \\
\hline Menzies $^{7}$ & 418 & 717 & 78 & \\
\hline \multicolumn{5}{|l|}{ Regimen 2RZ } \\
\hline $\operatorname{Lee}^{8}$ & 148 & 9459 & 57 & $\begin{array}{l}\text { Female OR } 4.1(95 \% \mathrm{Cl} 1.2 \text { to } 14.3) \\
\text { Recent conversion OR } 14.3(95 \% \mathrm{Cl} 1.8 \text { to } \\
\text { 115) }\end{array}$ \\
\hline Jasmer $^{3}$ & 307 & 7700 & 61 & $\begin{array}{l}\text { Age }>35 \text { OR } 12.2(95 \% \mathrm{Cl} 1.49 \text { to } 100.3) \\
\text { OR } 8.46 \times \text { isoniazid }(95 \% \mathrm{Cl} 1.9 \text { to } 76.5)\end{array}$ \\
\hline Stout $^{9}$ & 114 & 5300 & 67.5 & \\
\hline Weighted average & 569 & 6648 & & \\
\hline
\end{tabular}


taken and treatment duration), a clinical examination, a chest x-ray and, if appropriate, an IGRA test. (D)

2. Any patient with $C K D$ with an abnormal chest $x$-ray consistent with past $\mathrm{TB}$, or a previous history of extrapulmonary TB but who has previously received adequate treatment should be monitored regularly and considered for referral to and assessment by a specialist with an interest in TB, either a thoracic or infectious disease physician. (D)

3. Routine assessment of patients with CKD or those on haemodialysis or peritoneal dialysis with a TST or IGRA test is not recommended. Renal physicians may wish to assess individual patients at high risk of LTBI with an IGRA test (with or without a TST, a negative test being unhelpful) and discuss the results with a chest/infectious disease specialist in TB. (D)

4. Patients on the waiting list for renal transplantation may be assessed with an IGRA test (with or without a TST as above), giving the opportunity for chemoprophylaxis before transplantation. An individual risk assessment can be made using tables 1-3. In general, all black African and Asian patients born outside the UK should be screened and considered for chemoprophylaxis prior to or after transplantation. (D)

\subsection{Chemoprophylaxis}

5. The decision on chemoprophylaxis regimen should be made by the thoracic or infectious disease physician after discussion with both the patient and renal team. (D)

6. In general, isoniazid and rifampicin can be used in normal doses in renal impairment, during dialysis and following transplantation (see below). (D)

7. For chemoprophylaxis use 6 months of isoniazid $300 \mathrm{mg}$ daily plus pyridoxine $10-25 \mathrm{mg}$ daily, or isoniazid plus rifampicin (as Rifinah) plus pyridoxine for 3 months or rifampicin alone for 4-6 months. Any of these regimens is adequate for chemoprophylaxis. Long-term use of isoniazid is not recommended. (A)

8. There is no evidence to support chemoprophylaxis regimens of longer than 6 months for isoniazid alone, 3 months for isoniazid plus rifampicin, or 4-6 months for rifampicin alone. (A)

9. There is no evidence to support use of lower doses. These are inadequate for treatment of LTBI and lead to lower peak levels and possible development of drug resistance. (D)

10. If patients who have had chemoprophylaxis develop symptoms suggestive of clinical TB, they should be promptly and appropriately investigated. (A)

From tables 1, 2 and 3 it can be seen that all non-white patients and those born abroad and living in the UK for $<5$ years are at greater risk of reactivating TB than of hepatitis from chemoprophylaxis.

\section{DIAGNOSIS OF ACTIVE TB}

A history of previous TB, the drugs used for treatment and duration of treatment should be part of the routine assessment of all patients with $\mathrm{CKD}$, on dialysis or before transplantation. A history of recent contact with active pulmonary $\mathrm{TB}$ should also be sought. All patients with a chronic cough, unexplained weight loss or night sweats should have a chest x-ray and the appearances compared with earlier films. If new abnormalities are present, advice should be sought from a chest physician. Patients coughing up sputum should be asked to produce three consecutive early morning specimens for direct smear, culture and sensitivity. Those with new chest radiographic abnormalities who are not producing sputum should be investigated by induced sputum or flexible bronchoscopy, and mediastinal lymph nodes assessed with endobronchial ultrasoundguided transbronchial needle aspiration (EBUS-TBNA) or mediastinoscopy, depending on local availability.

Not all patients with renal disease who develop TB have classic symptoms and extrapulmonary disease is common, occurring in $30-50 \%$ of cases of TB in different series. ${ }^{33} 4243$ Quantrill and colleagues ${ }^{32}$ reported that $57 \%$ of cases of TB in patients on dialysis were peritoneal. Every effort should be made to obtain fluid or tissue for culture and sensitivity. Histological appearances of granulomas, with or without necrosis or caseation, can be useful but a portion of all biopsies should be sent in a plain pot (without formalin) to microbiology for culture.

\section{ANTITUBERCULOSIS DRUGS IN CHRONIC KIDNEY DISEASE}

The pharmacological properties of antituberculosis drugs determine how their levels are likely to be influenced by renal failure, clearance during dialysis and also their interaction with immunosuppressive drugs used in patients undergoing renal transplantation. These have been extensively reviewed, ${ }^{69-71}$ but considerable confusion still surrounds dosing of antituberculosis chemotherapy, dosage schedule, therapeutic drug monitoring,

Table 3 Sample calculations based on tables $1 A$ and $B$, and 2 (adapted from reference 10)

\begin{tabular}{|c|c|c|c|c|c|}
\hline Case & $\begin{array}{l}\text { Annual risk of } \\
\text { active TB/100 } 000\end{array}$ & $\begin{array}{l}\text { Effect of } \\
\text { CKD } \times 20\end{array}$ & $\begin{array}{l}\text { Effect of renal } \\
\text { transplant } \times 37\end{array}$ & $\begin{array}{l}\text { Risks of prophylaxis } \\
/ 100000 \text { (table 2) }\end{array}$ & $\begin{array}{l}\text { Risk/benefit type } \\
\text { calculation }\end{array}$ \\
\hline \multicolumn{6}{|l|}{ White } \\
\hline \multicolumn{6}{|l|}{ UK born } \\
\hline Age $35-54$ & 4 & 80 & 148 & 278 & Observation \\
\hline Age $55-74$ & 7 & 140 & 259 & 278 & Observation \\
\hline Indian subcontinent & 593 & 11860 & 17790 & 278 & Prophylaxis \\
\hline \multicolumn{6}{|l|}{ Age $>35$} \\
\hline \multicolumn{6}{|l|}{ In UK 3 years } \\
\hline Black-African & 168 & 3360 & 6216 & 278 & Prophylaxis \\
\hline \multicolumn{6}{|l|}{ Age $35-54$} \\
\hline Other ethnic group & 39 & 780 & 1443 & 278 & Prophylaxis \\
\hline \multicolumn{6}{|l|}{ Age $\geq 35$} \\
\hline In UK $>5$ years & & & & & \\
\hline
\end{tabular}

The weighted average risk for prophylaxis with $6 \mathrm{H}$ is $278 / 100000$ which is used for these calculations. That for $3 \mathrm{RH}$ is higher at 1766 100000 but may need to be considered if a shorter duration of chemoprophylaxis is needed on clinical grounds. CKD, chronic kidney disease. 
exact timing of administration in relation to dialysis and concomitant use of immunosuppressive drugs following renal transplantation. Treatment duration should, however, follow NICE guidelines-namely, 6 months for most cases of fully sensitive disease, with the exception of TB involving the CNS when treatment should be for 1 year. ${ }^{17}$

\subsection{Pharmacokinetics and toxicity of first-line therapy}

Overall, in patients with CKD the incidence of adverse effects attributable to their antituberculosis chemotherapy is significantly higher than that reported in patients with normal renal function. $^{72}$

\section{Isoniazid $(\mathrm{H})$}

Isoniazid is metabolised by the liver into less active compounds which are then excreted by the kidneys. The most recent evidence available suggests that isoniazid is dialysable in only very small amounts and most clearance occurs from hepatic metabolism. ${ }^{73}$ Isoniazid has been administered at a double dose three times a week along with dialysis sessions; however, this may result in an increased risk of neurotoxicity due to very high peak concentrations and so cannot be routinely recommended. There are no clear data on isoniazid elimination during peritoneal dialysis.

There was an unusually high incidence (37\%; 6 patients) of neuropsychiatric disturbance, with three cases of encephalopathy, in one series of 16 patients with TB receiving dialysis. ${ }^{74}$ Other side effects occurred in patients with $\mathrm{CKD}$ and $\mathrm{TB}$, but neuropsychiatric symptoms occurred exclusively in patients on dialysis. Symptoms usually developed within the first few weeks of treatment and included grand mal seizures (with no prior history), depressive psychosis, confusion, nightmares, hallucinations, peripheral neuropathy, twitching and dizziness. Encephalopathy was also reported in 3 of 48 dialysis patients with $\mathrm{TB},{ }^{33}$ and neuropsychiatric side effects due to isoniazid have been reported elsewhere in the literature as case reports. ${ }^{75-78}$ A quarter of those receiving dialysis also experienced significant gastrointestinal adverse effects (jaundice, nausea and vomiting).

Ototoxicity has been described over a 10-year period in seven patients with CKD receiving isoniazid together with other drugs but not aminoglycosides. ${ }^{79}$ In two patients this reversed upon withdrawal of isoniazid. Rarely, renal failure itself may be associated with hearing loss due to the underlying disease (eg, Alport syndrome, Wegener's granulomatosis) and by a variety of mechanisms such as axonal uraemic neuropathy ${ }^{80}$ and the increased susceptibility to ototoxins. ${ }^{81} 82$ Pharmacokinetic studies of isoniazid in renal failure, however, suggest that even though the half-life of isoniazid is increased by about $45 \%$ in slow acetylators, this does not lead to significant adverse events necessitating dosage reduction, and therapeutic drug monitoring is not thought to be necessary. ${ }^{83}$ Furthermore, there is evidence to suggest that administering isoniazid in reduced doses may lead to reduced potency and risk the development of resistance. ${ }^{84}$

\section{Rifampicin (R)}

Rifampicin is also metabolised by the liver. Its inactive metabolite, formylrifampicin, is excreted in the urine and its major metabolite, desacetyl-rifampicin, is excreted in bile. Urinary excretion accounts for very little of its elimination from the body, with only about $10 \%$ of a given dose being found unchanged in the urine. ${ }^{73}$ Rifampicin does not appear in significant amounts in dialysate. ${ }^{85}$ Reported side effects for rifampicin do not appear to occur with significantly increased frequency in patients with CKD or on dialysis, although rifampicin has been cited as a rare cause of acute renal failure. ${ }^{86}$ As such, there is widespread agreement that the dose of rifampicin need not be altered in renal impairment ${ }^{83}$ and that drug levels need not be monitored.

\section{Pyrazinamide $(Z)$}

Pyrazinamide is metabolised in the liver. Only $3-4 \%$ is renally excreted in unaltered form. ${ }^{87} 88$ Although the pharmacokinetics of the drug are unaltered initially in patients with renal failure, one study of its elimination found much higher levels detectable for up to $48 \mathrm{~h}$ after administration. ${ }^{89}$ Owing to its effect on uric acid retention, this may lead to hyperuricaemia and gout. Pyrazinamide and its metabolites are significantly eliminated from the body by haemodialysis, $45 \%$ appearing in the dialysate. $^{73}$ No data are available for peritoneal dialysis. Due to possible delayed elimination of the drug and its metabolite, the dosage interval should be altered in stages 4 and $5 \mathrm{CKD}$ and in patients on haemodialysis (table 4). There are no clear data for peritoneal dialysis.

\section{Ethambutol (E)}

Around $80 \%$ of ethambutol is excreted unchanged by the kidneys. $^{90-92}$ In patients with renal failure, excretion of ethambutol was significantly reduced following the usual dose of $15 \mathrm{mg} / \mathrm{kg} .^{93}$ It is renally excreted and ocular toxicity is largely dose-dependent. ${ }^{94}$ Ethambutol has been detected in dialysate.

It has improved efficacy when administered in high doses less often than in a daily lower dose. ${ }^{83}$ Serum monitoring should be done and trough levels should be less than $1.0 \mu \mathrm{g} / \mathrm{ml}$ at $24 \mathrm{~h}$ post-dose without dialysis.

Table 4 Recommended doses of first-line drugs in chronic kidney disease (CKD)

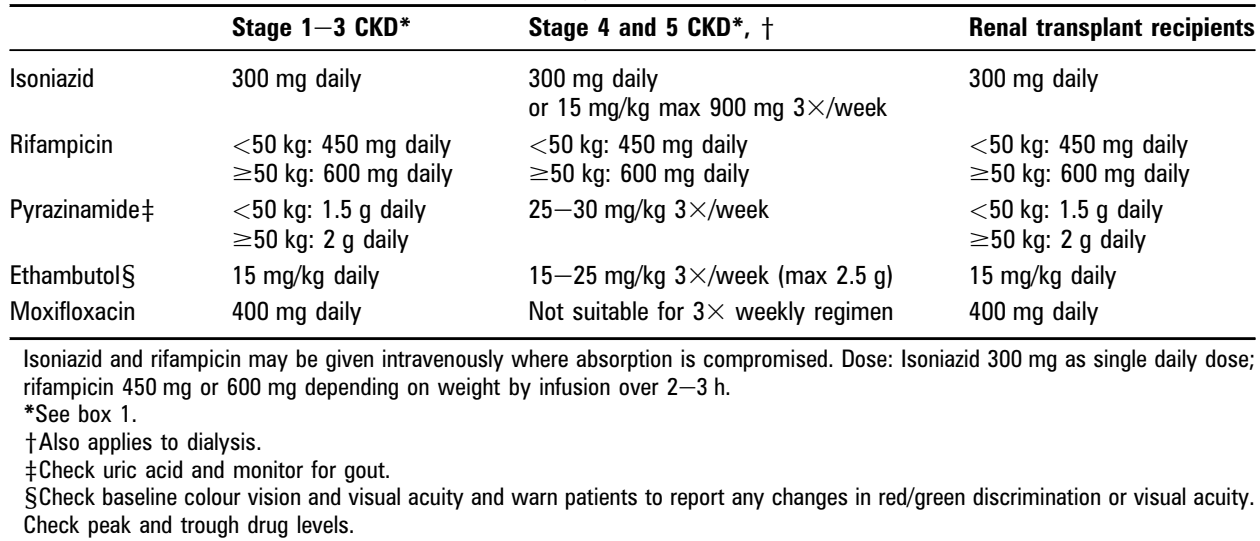


Aminoglycosides

Around $80 \%$ of streptomycin, kanamycin, amikacin and capreomycin are excreted unchanged in the urine without having undergone significant metabolism. ${ }^{83}$ Streptomycin causes significant vestibular toxicity but less nephrotoxicity compared with the other aminoglycosides. There is an increase in elimination time with increasing age and declining renal function. ${ }^{95}$ Approximately $40 \%$ of streptomycin, amikacin, capreomycin and kanamycin are removed by haemodialysis when these drugs are given just before haemodialysis. ${ }^{96}$ There are no available data on peritoneal dialysis. As with ethambutol and pyrazinamide, the dosing interval should be increased rather than the dose decreased as the drugs exhibit concentrationdependent bactericidal action, and lower doses may reduce drug efficacy. ${ }^{97}$ The American Thoracic Society (ATS) recommends $12-15 \mathrm{mg} / \mathrm{kg} /$ dose 2 or 3 times/week for all of these drugs. ${ }^{1}$ Drug levels should be monitored.

\section{RECOMMENDATIONS FOR THE MANAGEMENT AND TREATMENT OF ACTIVE TB}

11. If active $T B$ is suspected, every effort should be made to isolate an organism for sensitivity testing. (B)

12. Patients with active pulmonary disease should be isolated, preferably in negative pressure facilities. (D)

13. All cases of TB should be notified to the proper officer, usually the local consultant in Communicable Disease Control. (A)

14. Close cooperation between renal physicians and specialists in the management of TB is strongly recommended. (D)

15. Active TB should be excluded in patients with CKD by appropriate investigations in patients who have an abnormal chest x-ray or a history of prior pulmonary or extrapulmonary TB that has been either inadequately or not previously treated. Chemoprophylaxis should be given. (A)

16. TB should be considered in all patients with unexplained systemic or system-specific symptoms as extrapulmonary TB is common, particularly in patients on dialysis, with peritoneal TB being common in patients on chronic ambulatory peritoneal dialysis. (B)

17. Any patient with active TB, either pulmonary or nonpulmonary, should receive standard chemotherapy agents, albeit with dose interval modifications where appropriate (see text) and for standard duration as per NICE guidelines. (A)

18. Peak and trough drug levels should be monitored, particularly for ethambutol and the aminoglycosides, especially if there is concern regarding over- and under-dosing. (D)

All cases of active TB should be managed by the chest physician or infectious disease physician who is the local lead for $\mathrm{TB}$, in close collaboration with the renal physicians. The TB specialist nursing team should be informed so that appropriate contact tracing can be carried out. The management of active TB should follow NICE guidelines, ${ }^{17}$ with four drugs for the first 2 months followed by two drugs for a further 4 months for most cases of $\mathrm{TB}$ (with the exception of $\mathrm{TB}$ of the central nervous system where treatment should be for 1 year), unless drug resistance is suspected. If there are clinical signs and symptoms consistent with a diagnosis of $\mathrm{TB}$, treatment should be started without waiting for culture results. Patients with proven pulmonary TB should be isolated from other renal patients, preferably in a negative pressure room or, if this facility is not available, in a neutral pressure single room on a separate ward. Positive pressure rooms must not be used for patients with infectious TB. It is incumbent on the physician making the diagnosis of active TB to notify the case to the local consultant in Communicable Disease Control. In London, notification is via the London TB Register. If signs and symptoms were consistent with TB and there has been a response to treatment, the appropriate drug regimen should be continued even if subsequent culture results are negative.

\subsection{Patients with CKD not on dialysis}

19. For patients with stages 4 and $5 \mathrm{CKD}$, dosing intervals should be increased to three times weekly for ethambutol, pyrazinamide and the aminoglycosides. (D)

In general, isoniazid $(\mathrm{H})$, rifampicin $(\mathrm{R})$ and pyrazinamide $(\mathrm{Z})$ can be used in normal doses in renal impairment. Controlled clinical trials have shown that three times weekly treatment with pyrazinamide is therapeutically more effective than daily administration. ${ }^{1} 8398$ Pyridoxine supplementation should be given with isoniazid to prevent the development of peripheral neuropathy. In patients with severe renal impairment (without dialysis), some authors advocate reducing the dose of isoniazid to $200 \mathrm{mg}$ once daily but there is no evidence to support this Ethambutol (E) is also predominantly removed by the kidney and dose reduction or preferably increasing the dose interval with therapeutic drug monitoring is mandatory. Recommended doses in relation to creatinine clearance are shown in table 4.

The fourth drug is needed because of the rising rate of isoniazid resistance (7\% in England and Wales) and the disproportionate number of ethnic minority cases with CKD. Ethambutol and the aminoglycosides have the disadvantage of renal clearance, the need for increased dose intervals or reduced dosage and drug monitoring. Recent data have shown that gatifloxacin and moxifloxacin are at least equivalent and possibly superior to ethambutol as the fourth drug in treatment. ${ }^{99} 100$ If there is concern about ethambutol toxicity, an alternative to the usual induction regimen of daily RHZE for the first 2 months of treatment would be daily RHZMoxi for the first 2 months. Although usually well tolerated, there is evidence for connective tissue disorders with the quinolones, dysglycaemia with gatifloxacin and liver dysfunction and a long QT interval with moxifloxacin (reviewed by Mehlhorn and Brown ${ }^{101}$ ). If there is culture confirmation of fully sensitive TB before 2 months, then the fourth drug (ethambutol or moxifloxacin) may be stopped early. This regimen using moxifloxacin instead of ethambutol is only suitable for daily treatment and cannot be used for a three times weekly regimen.

\subsection{Haemodialysis}

20. For patients on haemodialysis, dosing intervals should be increased to three times weekly to reduce the risk of drug accumulation and toxicity. (D)

21. Treatment can be given immediately after haemodialysis to avoid premature drug removal. With this strategy there is a possible risk of raised drug levels of ethambutol and pyrazinamide between dialysis sessions. Alternatively, treatment can be given $4-6 \mathrm{~h}$ before dialysis, increasing the possibility of premature drug removal but reducing possible ethambutol or pyrazinamide toxicity. The choice of strategy may be influenced by a need to ensure adherence (when post dialysis offers the opportunity for directly observed therapy), practical issues (post dialysis for morning shift patients) and expected pharmacokinetics or drug interactions. (D) 
Both rifampicin and isoniazid may be given in their usual daily doses. Haemodialysis removes a significant amount of pyrazinamide and the primary metabolite of pyrazinamide, pyrazinoic acid, accumulates in patients with renal failure. ${ }^{73}$ Advice varies over whether reduction or spacing of the dose of pryazinamide is best for patients on haemodialysis. Variable doses of $25-30 \mathrm{mg} / \mathrm{kg}$ three times weekly ${ }^{73}$ or $40 \mathrm{mg} / \mathrm{kg}$ three times weekly ${ }^{83}$ have been recommended. The American guidelines generally recommend a change in dose frequency rather than dose level because, although toxicity may be avoided by reducing the dose, the peak serum concentrations may be too low, leading to suboptimal treatment. ${ }^{1}$ Pyrazinamide should be administered immediately after haemodialysis or 4-6 h beforehand. Ethambutol can be given at a dose of $15-25 \mathrm{mg} / \mathrm{kg}$ three times weekly for patients on regular haemodialysis. Some authorities recommended dosing $4-6 \mathrm{~h}$ before haemodialysis, ${ }^{83}$ while others recommend post-dialysis treatment using the same doses, avoiding loss of drugs during dialysis and facilitating adherence. ${ }^{173} 102$

\subsection{Peritoneal dialysis}

Mechanisms for drug removal differ between haemodialysis and peritoneal dialysis so it cannot be assumed that recommendations for haemodialysis also apply to peritoneal dialysis. Such patients may require careful monitoring including measurement of drug levels. One study has shown that no dose adjustment is needed for isoniazid, rifampicin or pyrazinmide for the treatment of systemic or pulmonary TB in patients on CAPD. ${ }^{103}$ Rifampicin has a high molecular weight, lipid solubility and protein binding capacity and these properties make it less dialysable through the peritoneal membrane so that only minimal amounts are recovered in the dialysate, implying that oral therapy with rifampicin may not be adequate for treatment of peritoneal TB. Ahn and colleagues suggest intraperitoneal administration of rifampicin should be considered when treating peritoneal TB. ${ }^{103}$

\subsection{Critically ill patients on continuous renal replacement therapy}

There are no studies on the management of critically ill patients with $\mathrm{TB}$ and renal failure on continuous renal replacement therapy (continuous venovenous haemodialysis or continuous venovenous haemo(dia)filtration). In principle, the treatment should follow NICE guidelines ${ }^{17}$ but the exact choice of drugs and dosing will depend on associated comorbidities and interaction with other drugs. Close collaboration between critical care pharmacists, respiratory (and/or infectious diseases physicians) and the renal team is essential. Monitoring of drug levels (where possible) is strongly recommended.

\subsection{Renal transplantation}

22. Rifampicin in particular can interact with immunosuppressive regimens, increasing the chance of graft rejection, and doses of mycophenolate mofetil, tacrolimus and ciclosporin may need adjustment. Corticosteroid doses should be doubled in patients receiving rifampicin. (B)

Renal function usually improves after transplantation but can vary. Dose modifications may be necessary depending on the level of transplant function (table 4) and additional drugs, and levels should be monitored. In general, standard therapy for 6 months of 2RHZE/M followed by 4RH should be used. ${ }^{1} 17104$

Antituberculosis drug interactions with immunosuppressive drugs are important and can lead to graft rejection. Rifampicin is the drug most likely to interfere with immunosuppressive treatment by induction of a number of liver enzymes including uridine diphosphate-glucuronosyltransferases, monoamine oxidases, glutathione S-transferases and cytochrome P450. A number of important immunosuppressive drugs depend on these enzymes for their metabolism. The daily corticosteroid dose should be increased to twice the baseline dosage in patients taking rifampicin. Rifampicin also lowers blood levels of ciclosporin, which should be monitored and the dose adjusted. Information on the extent, duration and potency of the rifampin-tacrolimus interaction is limited. There are case reports describing renal transplant recipients who demonstrated an increase in tacrolimus metabolism as a result of rifampicin administration. ${ }^{105106}$ Patients should be monitored for reduced plasma levels of tacrolimus and doses of tacrolimus may need to be increased. ${ }^{107}$ Rifampicin also interacts with mycophenolate mofetil by induction of hepatic, renal and gastrointestinal uridine diphosphate-glucuronosyltransferases and organic anion transporters with resulting functional inhibition of enterohepatic recirculation of mycophenolate. ${ }^{108}$ Once rifampicin has been stopped, liver enzyme induction usually takes 2 weeks to return to normal.

Azathioprine sometimes causes hepatotoxicity, which has to be differentiated from the hepatotoxicity due to antituberculosis drugs.

\section{SUGGESTED AUDIT CRITERIA}

Suggested audit criteria are as follows:

- History of previous TB or contact checked? (Y/N)

- If at risk for $\mathrm{TB}$, has a chest X-ray (and IGRA test if appropriate) been performed? (Y/N)

- If chest X-ray is abnormal, has active TB been excluded? (Y/N)

- If active or latent disease, has patient been referred to a TB specialist? $(\mathrm{Y} / \mathrm{N})$

- Chemoprophylaxis given for the appropriate time for latent disease? $(\mathrm{Y} / \mathrm{N})$

- Full treatment given with appropriate dose/interval modifications given for active disease? $(\mathrm{Y} / \mathrm{N})$

- Peak and trough drug levels monitored where appropriate? $(\mathrm{Y} / \mathrm{N})$

Competing interests All members of the Guidelines Committee were asked to submit a written record of possible conflicts of interest to the Standards of Care Committee of the BTS. PD has acted as an advisor for Oxford Immunotec (UK) and has received an honorarium. No other conflicts of interest were declared.

Provenance and peer review Not commissioned; not externally peer reviewed

\section{REFERENCES}

1. Blumberg HM, Burman WJ, Chaisson RE, et al. American Thoracic Society/Centers for Disease Control and Prevention/Infectious Diseases Society of America: Treatment of tuberculosis. Am J Respir Crit Care Med 2003;167:603-62. (I+).

2. International Union Against Tuberculosis Committee on Prophylaxis. Efficacy of various durations of isoniazid preventive therapy for tuberculosis: five years of follow-up in the IUALTD trial. Bull World Health Organ 1982;60:555-64. $(2++)$.

3. Jasmer RM, Saukkonen JJ, Blumberg HM, et al. Short course rifampicin and pyrazinamide compared with isoniazid for latent tuberculosis infection: a multicentre clinical trial. Ann Intern Med 2002;137:640-7. (I-).

4. Nolan CM, Goldberg SV, Buskin SE. Hepatotoxicity associated with isoniazid preventive therapy: a seven year survey from a public health tuberculosis clinic. JAMA 1999;281:1014-18. (2+).

5. Bailey EC, Taylor SL, Dascomb HE, et al. Disturbed hepatic function during isoniazid chemoprophylaxis. Am Rev Respir Dis 1973;107:523-9. (2+).

6. Hong Kong Chest Service, Tuberculosis Research Centre Madras, and British Medical Research Council. A double-blind placebo-controlled clinical trial of three antituberculosis chemoprophylaxis regimens in patients with silicosis in Hong Kong. Am Rev Respir Dis 1992;145:36-41. $(1++)$.

7. Menzies D, Long R, Trajman A, et al. Adverse events with 4 months of rifampin therapy or 9 months of isoniazid therapy for latent tuberculosis infection: a randomized trial. Ann Intern Med 2008;149:689-97. (1-).

8. Lee AM, Mennone JZ, Jones RC, et al. Risk factors for hepatotoxicity associated with rifampicin and pyrazinamide for the treatment of latent tuberculosis infection: experience from three public health tuberculosis clinics. Int J Tuberc Lung Dis 2002;6:995-1000. $(2+)$

9. Stout JE, Engemann JJ, Cheng AC, et al. Safety of two months rifampicin and pyrazinamide for treatment of latent tuberculosis. Am J Respir Crit Care Med 2003;167:824-7. $(2+)$. 
10. British Thoracic Society Standards of Care Committee. BTS recommendations for assessing risk and for managing Mycobacterium tuberculosis infection and disease in patients due to start anti-TNF- $\alpha$ treatment. Thorax 2005;60:800-5. (I-).

11. Kay NE, Raij LR. Immune abnormalities in renal failure and hemodialysis. Blood Purif 1986:4:120-9. $(2++)$.

12. Gibbons RAS, Martinez OM, Garovoy MR. Altered monocyte function in uraemia. Clin Immunol Immunopathol 1990;56:66-71. (2+).

13. Holick MF. Vitamin D deficiency. N Engl J Med 2007;357:266-81. (I+)

14. Lundin AP, Adler AJ, Berlyne GM, et al. Tuberculosis in patients undergoing maintenance hemodialysis. Am J Med 1979;67:597-602. (3).

15. Chia S, Karim M, Elwood RK, et al. Risk of tuberculosis in dialysis patients: a population-based study. Int J Tuberc Lung Dis 1998:2:989-91. (3).

16. Andrew OT, Schoenfeld PY, Hopewell PC, et al. Tuberculosis in patients with endstage renal disease. Am J Med 1980;68:59-65. (3).

17. The National Collaborating Centre for Chronic Conditions. Tuberculosis. Clinical diagnosis and management of tuberculosis and measures for its prevention and control. March 2006. http://www.nice.org.uk/nicemedia/pdf/ CG033FullGuideline.pdf. $(I++)$.

18. CDC and MMWR. Targeted tuberculin testing and treatment of latent tuberculosis infection. 9 June 2000/Nol. 49/No. RR-6. http://www.cdc.gov/mmwr/PDF/rr/rr4906. pdf. $(I-)$.

19. Aguado HM, Torre-Cisneros J, Fortun J, et al. Tuberculosis in solid-organ transplant recipients: Consensus statement of the Group for the Study of Infection in Transplant Recipients (GESITRA) of the Spanish Society of Infectious Diseases and Clinical Microbiology. Clin Infect Dis 2009;48:1276-84. (I-).

20. Smirnoff M, Patt G, Seckler R, et al. Tuberculin and anergy skin testing of patients receiving long-term hemodialysis. Chest 1998;113:25-7 (2-)

21. Shankar MS, Aravindan AN, Sohal PM, et al. The prevalence of tuberculin sensitivity and anergy in chronic renal failure in an endemic area: tuberculin test and the risk of post-transplant tuberculosis. Nephrol Dial Transplant 2005;20:2720-4. (2+).

22. Poduval RD, Hammes MD. Tuberculosis screening in dialysis patients: is the tuberculin test effective? Clin Nephrol 2003;59:436-40. (2+).

23. Woeltje KF, Mathew $A$, Rothstein $\mathrm{M}$, et al. Tuberculosis infection and anergy in hemodialysis patients. Am J Kidney Dis 1998:31:848-52. (2-).

24. Wojnar RJ, Brittain RJ, Dzelzkalns E. Effect of nonsteroidal anti-inflammatory and other pharmacological agents on tuberculin reaction. J Pharm Sci 1979;68:12-15. (2+).

25. Balcells ME, Thomas SL, Godfrey-Faussett $P$, et al. Isoniazid preventive therapy and risk for resistant tuberculosis. Emerg Infect Dis 2006;12:744-51. (I+).

26. Amedia C. Oettinger CW. Unusual presentation of tuberculosis in chronic hemodialysis patients. Clin Nephrol 1977;8:363-6. (3).

27. Lightstone L. Preventing renal disease: the ethnic challenge in the United Kingdom. Kidney Int 2003:63:S135-8. $(2++)$

28. Yuan FH, Guang LX, Zhao SJ. Clinical comparisons of 1,498 chronic renal failure patients with and without tuberculosis. Ren Fail 2005;27:149-53. (2+).

29. Rutsky EA, Rostand SG. Mycobacteriosis in patients with chronic renal failure. Arch Intern Med 1980;140:57-61. (3).

30. Ahmed AT, Karter AJ. Tuberculosis in California dialysis patients. Int J Tuberc Lung Dis 2004;8:341-5. (2-).

31. Sen N, Turenc T, Karatasli M, et al. Tuberculosis in patients with end-stage renal disease undergoing dialysis in an endemic region of Turkey. Transplant Proc 2008:40:81-4. (3)

32. Quantrill SJ, Woodhead MA, Bell CE, et al. Peritoneal tuberculosis in patients receiving continuous ambulatory peritoneal dialysis. Nephrol Dial Transplant 2001:16:1024-7. (3)

33. Malik GH, Al-Harbri AS, Al-Mohaya $\mathrm{S}$, et al. Eleven years of experience with dialysis associated tuberculosis. Clin Nephrol 2002:58:356-62. (3).

34. Riska H, Gronhagen-Riska C, Ahonen J. Tuberculosis and renal allograft transplantation. Transplant Proc 1987:19:4096-7. (2+).

35. McWhinney N, Khan 0, Williams G. Tuberculosis in patients undergoing maintenance haemodialysis and renal transplantation. Br J Surg 1981;68:408-11. (3).

36. Lichtenstein IH, MacGregor RR. Mycobacterial infections in renal transplant recipients: report of five cases and review of the literature. Rev Infect Dis 1983;5:216-26. (3)

37. Lloveras J, Peterson PK, Simmons RL, et al. Mycobacterial infections in renal transplant recipients. Seven cases and a review of the literature. Arch Intern Med 1982;142:888-92. (3).

38. Ergun I, Ekmekci Y, Sengul S, et al. Mycobacterium tuberculosis infection in renal transplant recipients. Transplant Proc 2006;38:1344-5. (3).

39. Atasever A, Bacakoglu F, Toz $\mathrm{H}$, et al. Tuberculosis in renal transplant recipients on various immunosuppressive regimens. Nephrol Dial Transplant 2005;20:797-802. (2+).

40. Abbott KC, Klote MM. Update on guidelines for prevention and management of Mycobacterium tuberculosis infections after transplant. Am J Transplant 2005;5 (5):1163. $(1+)$.

41. Queipo JA, Broseta E, Santos M, et al. Mycobacterial infection in a series of 1261 renal transplant recipients. Clin Microbiol Infect 2003:9:518-25. (3).

42. Vandermarliere A, Van Audenhove A, Peetermans WE, et al. Mycobacteria infection after renal transplantation in a Western population. Transpl Infect Dis 2003:5:9-15. (3)

43. Chen $\mathbf{C H}$, Lian JD, Cheng $\mathrm{CH}$, et al. Mycobacterium tuberculosis infection following renal transplantation in Taiwan. Transpl Infect Dis 2006:8:148-56. (3).

44. Agarwal DK, Dash SC, Tiwari SC, et al. Spectrum of tuberculosis in renal transplant recipients in northern India. Indian J Nephrol 1992;2:39-43. (3).
45. Sakhuja V, Jha V, Verma PP, et al. The high incidence of tuberculosis among renal transplant recipients in India. Transplantation 1996;61:211-15. (3).

46. Hariharan S, Date A, Gopalkrishnan G, et al. Tuberculosis after renal transplantation. Dialysis Transp/ 1987:16:311-12. (3).

47. John GT, Shankar V. Mycobacterial infections in organ transplant recipients. Semin Respir Infect 2002:17:274-83. (2++).

48. Basiri A, Moghaddam SM, Simforoosh N, et al. Preliminary report of a nationwide case-control study for identifying risk factors of tuberculosis following renal transplantation. Transplant Proc 2005:37:3041-4. (2+).

49. Zhang XF, Lv Y, Xue WJ, et al. Mycobacterium tuberculosis infection in solid organ transplant recipients: experience from a single centre in China. Transplant Proc 2008:40:1382-5. (3).

50. Mack U, Migliori GB, Sester M, et al. LTBI: latent tuberculosis infection or lasting immune responses to M. tuberculosis? A TBNET consensus statement. Eur Respir J 2009:33:956-73. (I+)

51. Ferrara G, Losi M, D'Amico R, et al. Use in routine clinical practice of two commercial blood tests for diagnosis of infection with Mycobacterium tuberculosis: a prospective study. Lancet 2006;367:1328-34. (2+).

52. Passalent LKK, Richardson R, Wang J, et al. Detecting latent tuberculosis infection in haemodialysis patients: a head to head comparison of the T-SPOT TB test, tuberculin skin test and an expert physician panel. Clin J Am Soc Nephrol 2007; 2:68-73. $(2+)$

53. Winthrop KL, Nyendak M, Calvet $\mathrm{H}$, et al. Interferon- $\gamma$ release assays for diagnosing Mycobacterium tuberculosis infection in renal dialysis patients. Clin J Am Soc Nephrol 2008:3:1357-63. (2+).

54. Triverio PA, Bridevaux PO, Roux-Lombard P, et al. Interferon-gamma release assays versus tuberculin skin testing for detecting of latent tuberculosis in chronic haemodialysis patients. Nephrol Dial Transplant 2009:24:2186-9. (2+).

55. Lee SS, Chou KJ, Su IJ, et al. High prevalence of latent tuberculosis infection in patients in end-stage renal disease on haemodialysis: Comparison of QuantiFERON TB GOLD, ELISPOT and tuberculin skin test. Infection 2009;37:96-102. (2+).

56. American Thoracic Society and Centres for Disease Control and Prevention. Targeted tuberculin testing and treatment of latent tuberculosis infection. Am J Respir Crit Care Med 2000:161:S221-47. (2++).

57. Centres for Disease Control. Fatal and severe hepatitis associated with rifampicin and pyrazinamide for the treatment of latent tuberculosis infection - New York and Georgia, 2000. MMWR Morbidity Mortality Weekly Report 2001;50:289-91. $(2++)$.

58. Centres for Disease Control. Update: Fatal and severe liver injuries associated with rifampicin and pyrazinamide for latent tuberculosis infection, and revisions in the American Thoracic Society/CDC recommendations-United States 2001. MMWR Morbidity Mortality Weekly Report 2001;50:733-5. $(2++)$

59. Joint Tuberculosis Committee of the British Thoracic Society. Control and prevention of tuberculosis: recommendations 2000. Thorax 2000;55: 887-901. $(2++)$

60. Vikrant S, Agarwal SK, Gupta S, et al. Prospective randomized control trial of isoniazid chemoprophylaxis during renal replacement therapy. Transpl Infect Dis 2005;7:99-108. (1+).

61. Agarwal SK, Gupta S, Dash SC, et al. Prospective randomised trial of isoniazid prophylaxis in renal transplant recipients. Int Urol Nephrol 2004;36:425-31. (I+

62. Sayiner A, Ece T, Duman $\mathrm{S}$, et al. Tuberculosis in renal transplant recipients. Transplantation 1999:68:1268-71. (3).

63. Yildiz A, Sever MS, Turkmen A, et al. Tuberculosis after renal transplantation: experience of one Turkish centre. Nephrol Dial Transplant 1998;13:1872-5. (3).

64. Smieja MJ, Marchetti CA, Cook DJ, et al. Isoniazid for preventing tuberculosis in non-HIV infected persons. Cochrane Database Syst Rev 1999;(1):CD001363. Cochrane Library, 2010, Issue 1. (I+).

65. Kumar D, Watson JM, Charlett A, et al. Tuberculosis in England and Wales in 1993: results of a national survey. Thorax 1997:52:1060-7. (2+).

66. Rose AMC, Watson JM, Graham C, et al. Tuberculosis at the end of the $20^{\text {th }}$ century in England and Wales: results of a national survey in 1998. Thorax 2001:56 173-9. $(2+)$

67. Pozniak A, Ormerod JP, Miller R. Treatment of tuberculosis in HIV-infected patients. AIDS 1999:13:435-45. (4).

68. Ormerod P, Novelli V, Pozniak A, et al. Joint Tuberculosis Committee of the British Thoracic Society. Chemotherapy and management of tuberculosis in the United Kingdom: recommendations 1998. Thorax 1998;53:536-48. (I+).

69. Weber WW, Hein DW. Clinical pharmacokinetics of isoniazid. Clin Pharmacokinet 1979; $4: 401-22 .(2++)$

70. Kenny MT, Strates B. Metabolism and pharmacokinetics of the antibiotic rifampin. Drug Metab Rev 1981;12:159-218. (2++).

71. Holdiness MR. Clinical pharmacokinetics of the antituberculosis drugs. Clin Pharmacokinet 1984;9:511-44. (2++).

72. Ormerod LP, Horsfield N. Frequency and type of reactions to antituberculosis drugs: observations in routine treatment. Tuberc Lung Dis 1996;77:37-42. (3).

73. Malone RS, Fish DN, Spiegel DM, et al. The effect of hemodialysis on isoniazid, rifampin, pyrazinamide, and ethambutol. Am J Respir Crit Care Med 1999:159:1580-4. (2+)

74. Quantrill SJ, Woodhead MA, Bell CE, et al. Side-effects of antituberculosis drug treatment in patients with chronic renal failure. Eur Respir J 2002;20:440-3. (3)

75. Cheung WC, Lo CY, Lo WK, et al. Isoniazid induced encephalopathy in dialysis patients. Tuber Lung Dis 1993;74:136-9. (3). 
76. Siskind MS, Thienemann D, Kirlin L. Isoniazid-induced neurotoxicity in chronic dialysis patients: report of three cases and a review of the literature. Nephron 1993;64:303-6. (3).

77. Wang HY, Chien CC, Chen YM, et al. Encephalopathy caused by isoniazid in a patient with end stage renal disease with extrapulmonary tuberculosis. Ren Fail 2003:25:135-8. (3).

78. Blumberg EA, Gil RA. Cerebellar syndrome caused by isoniazid. DICP 1990;24:829-31. (3)

79. Altiparmak MR, Pamuk ON, Pamuk GE, et al. Is isoniazid ototoxic in patients undergoing hemodialysis? Nephron 2002;92:478-80. (3).

80. Shaheen FA, Mansuri NA, al-Shaikh AM, et al. Reversible uremic deafness: is it correlated with the degree of anemia? Ann Otol Rhinol Laryngol 1997;106:391-3. (2+).

81. Gendeh BS, Gibb AG, Aziz NS, et al. Vancomycin administration in continuous ambulatory peritoneal dialysis: the risk of ototoxicity. Otolaryngol Head Neck Surg 1998;118:551-8. (2-)

82. Manian FA, Stone WJ, Alford RH. Adverse antibiotic effects associated with renal insufficiency. Rev Infect Dis 1990;12:236-49. $(2++)$

83. Ellard GA. Chemotherapy of tuberculosis for patients with renal impairment Nephron 1993;64:169-81. $(2++)$.

84. East African/British Medical Research Council. Isoniazid with thiacetazone in the treatment of pulmonary tuberculosis in East Africa: Second investigation. Tubercle 1963; 44:301-33. (2+).

85. Acocella G, Mattiussi R, Segre G. Multicompartmental analysis of serum, urine and bile concentrations of rifampicin and desacetyl-rifampicin in subjects treated for one week. Pharmacol Res Commun 1978;10:271-88. $(2+1$.

86. Rekha VV, Santha T, Jawahar MS. Rifampicin-induced renal toxicity during retreatment of patients with pulmonary tuberculosis. J Assoc Physicians India 2005:53:811-13. (3)

87. Lacroix C, Hoang TP, Nouveau J, et al. Pharmacokinetics of pyrazinamide and its metabolites in healthy subjects. Eur J Clin Pharmacol 1989;36:395-400. (2+).

88. Ellard GA. Absorption, metabolism and excretion of pyrazinamide in man. Tubercle 1969;50:144-58. $(2+)$

89. Stamatakis G, Montes C, Trouvin JH, et al. Pyrazinamide and pyrazinoic acid pharmacokinetics in patients with chronic renal failure. Clin Nephrol 1988;30:230-4. $(2+)$

90. Peets EA, Sweeney WM, Place VA, et al. The absorption, excretion and metabolic fate of ethambutol in man. Am Rev Respir Dis 1965;91:51-8. $(2++)$

91. Lee CS, Gambertoglio JG, Brater DC, et al. Kinetics of oral ethambutol in the normal subject. Clin Pharmacol Ther 1977;22:615-21. (2+).

92. Lee CS, Brater DC, Gambertoglio JG, et al. Disposition kinetics of ethambutol in man. J Pharmacokinet Biopharm 1980;8:335-46. $(2+)$.

93. Varughese A, Brater DC, Benet LZ, et al. Ethambutol kinetics in patients with impaired renal function. Am Rev Respir Dis 1986;134:34-8. (2+).

94. Citron K. Ethambutol: a review with special reference to ocular toxicity. Tubercle 1969:50(Suppl):32-6. $(2++)$

95. Line DH, Poole GW, Waterworth PM. Serum streptomycin levels and dizziness. Tubercle 1970:51:76-81. (3).

96. Matzke GR, Halstenson CE, Keane WF. Hemodialysis elimination rates and clearance of gentamicin and tobramycin. Antimicrob Agents Chemother 1984:25:128-30. (3)

97. Peloquin CA. Using therapeutic drug monitoring to dose the antimycobacterial drugs. Drugs 2002;62:2169-83. (I+)

98. Panchagnula R, Kaur KJ, Singh I, et al. The WHO simplified study protocol in practice: investigation of combined formulations supplied by the WHO. Int J Tuberc Lung Dis 1999;3(11 Suppl 3):S336-42; discussion S351-2. $(2++)$

99. Burman WJ, Goldberg S, Johnson JC, et al. Moxifloxacin versus ethambutol in the first two months of treatment for pulmonary tuberculosis. Am J Respir Crit Care Med 2006;174:331-8. (I).

100. Rustomjee R, Lienhardt C, Kanyok T, et al. Gatifloxacin for TB (OFLOTUB) study team. A phase II study of the sterilising activity of ofloxacin, gatifloxacin and moxifloxacin in pulmonary tuberculosis. Int J Tuberc Lung Dis 2008;12:128-38. (1+).

101. Mehlhorn AJ, Brown DA. Safety concerns with fluoroquinolones. Ann Pharmacother 2007:41:1859-66. (I+).

102. Launay-Vacher V, Izzedine $H$, Deray G. Pharmacokinetic considerations in the treatment of tuberculosis in patients with renal failure. Clin Pharmacokinet 2005:44:221-35. (I-).

103. Ahn C, Oh K-H, Kim K, et al. Effect of peritoneal dialysis on plasma and peritoneal fluid concentrations of isoniazid, pyrazinamide and rifampicin. Perit Dial Int 2003;23:362-7. (2-)

104. EBPG Expert Group in Renal Transplantation. European best practice guidelines for renal transplantation. Section IV: Long-term management of the transplant recipient; V.7.2 Late infections. Tuberculosis. Nephrol Dial Transplant 2002;17(Suppl 4):39-43. (I-)

105. Bhaloo S, Prasad GV. Severe reduction in tacrolimus levels with rifampin despite multiple cytochrome P450 inhibitors: a case report. Transplant Proc 2003;35:2449-51. (3).

106. Chenhsu RY, Loong CC, Chou MH, et al. Renal allograft dysfunction associated with rifampin-tacrolimus interaction. Ann Pharmacother 2000;34:27-31. (3)

107. Baxter K ed. Stockley's drug interactions (electronic version). London: Pharmaceutical Press, 2008. $(1+1$.
108. Kuypers DR, Verleden G, Naesens M, et al. Drug interaction between mycophenolate mofetil and rifampin: possible induction of uridine diphophateglucuronosyltransferase. Clin Pharmacol Ther 2005;78:81-8. (3).

109. Fish DN, Chow AT. The clinical pharmacokinetics of levofloxacin. Clin Pharmacokinet 1997:32:101-19. (I+).

110. Zhu M, Nix DE, Adam RD, et al. Pharmacokinetics of cycloserine under fasting conditions and with high-fat meal, orange juice, and antacids. Pharmacotherapy 2001;21:891-7. (I+).

111. Malone RS, Fish DN, Spiegel DM, et al. The effect of hemodialysis on cycloserine, ethionamide, para-aminosalicylate, and clofazimine. Chest 1999;116 984-90. $(2+)$.

112. Holdiness MR. Neurological manifestations and toxicities of the antituberculosis drugs. A review. Med Toxicol 1987;2:33-51. (I-).

113. Berns JSBM. Drug prescribing in renal failure: dosing guidelines for adults. 4th edn. Philadelphia, PA: American College of Physicians, 1999. $(I+)$

\section{APPENDIX: SECOND-LINE DRUGS USED IN THE MANAGEMENT OF RESISTANT DISEASE}

Patients developing drug-resistant disease will need treatment with second-line drugs.

This medication must be prescribed with the full involvement of a specialist with experience in the management of drug-resistant tuberculosis.

\section{Fluoroquinolones}

Both ofloxacin and ciprofloxacin are also dependent on renal clearance and doses should be reduced accordingly. Other fluoroquinolones undergo some degree of renal clearance which varies from drug to drug. Levofloxacin undergoes greater renal clearance than moxifloxacin. ${ }^{109}$

Recommendations for fluoroquinolone doses in end-stage renal disease provided by the manufacturers were developed for the treatment of pyogenic bacterial infections. The treatment of TB requires much longer courses of drugs, so these recommendations cannot be assumed to be applicable to the management of TB.

Fluoroquinolones decrease the metabolism of ciclosporin $A$ and displace it from the bound form, thus increasing its toxicity.

\section{Cycloserine}

Up to $70 \%$ of cycloserine is excreted by the kidney and $56 \%$ removed by haemodialysis. ${ }^{102} 110111$ Given that dose-related neurological and psychiatric side effects of cycloserine have been reported in up to $50 \%$ of patients, ${ }^{112}$ dose adjustment in the setting of renal failure is recommended. There are no specific data related to peritoneal dialysis.

The ATS recommends increasing the dose interval and suggests $250 \mathrm{mg}$ once daily or preferably $500 \mathrm{mg} 3$ times/week. Again, it should be given after haemodialysis to avoid under-dosing and monitored for neurotoxicity.

\section{Para-amino salicylic acid (PAS)}

A modest amount of PAS $(6.3 \%)$ is cleared by haemodialysis but its metabolite acetyl-PAS, is substantially removed. A dose of $4 \mathrm{mg}$ twice daily should be adequate.

\section{Ethionamide/prothionamide}

Ethionamide and prothionamide are not cleared by the kidneys nor are they removed by haemodialysis, so no adjustment to dosing is needed. ${ }^{11}$

\section{Clofazimine}

Clofazimine is available on a named patient basis. It can accumulate in CKD and causes skin and hair discolouration, photosensitivity and ocular problems. Pharmaceutical advice should be sought. The normal dose is $100-300 \mathrm{mg}$ daily and this should be reduced to three times weekly in patients with CKD and those on dialysis. ${ }^{111}$

\section{Linezolid}

A higher incidence of blood disorders and optic neuropathy has been reported if linezolid is used for longer than 28 days, making its use in the management of TB difficult. Linezolid is a reversible non-selective monoamine oxidase inhibitor and patients should avoid eating tyramine-rich foods such as cheese and products containing yeast. The normal dose is $600 \mathrm{mg}$ every $12 \mathrm{~h}$.

Other suggestions shown in table A1 have been drawn up from 'Drug Prescribing in Renal Failure' 4th edition ${ }^{113}$ and are approved by the FDA.

The ATS uses a creatinine clearance of $<30 \mathrm{ml} / \mathrm{min}$ as their cut-off point below which changes need to be made. There are insufficient data in patients with a reduced creatinine clearance but $>30 \mathrm{ml} / \mathrm{min}$. In these patients, standard doses can be given but measurement of serum levels is recommended where possible to avoid toxicity. 
Table A1 Second-line drugs in chronic kidney disease (CKD)

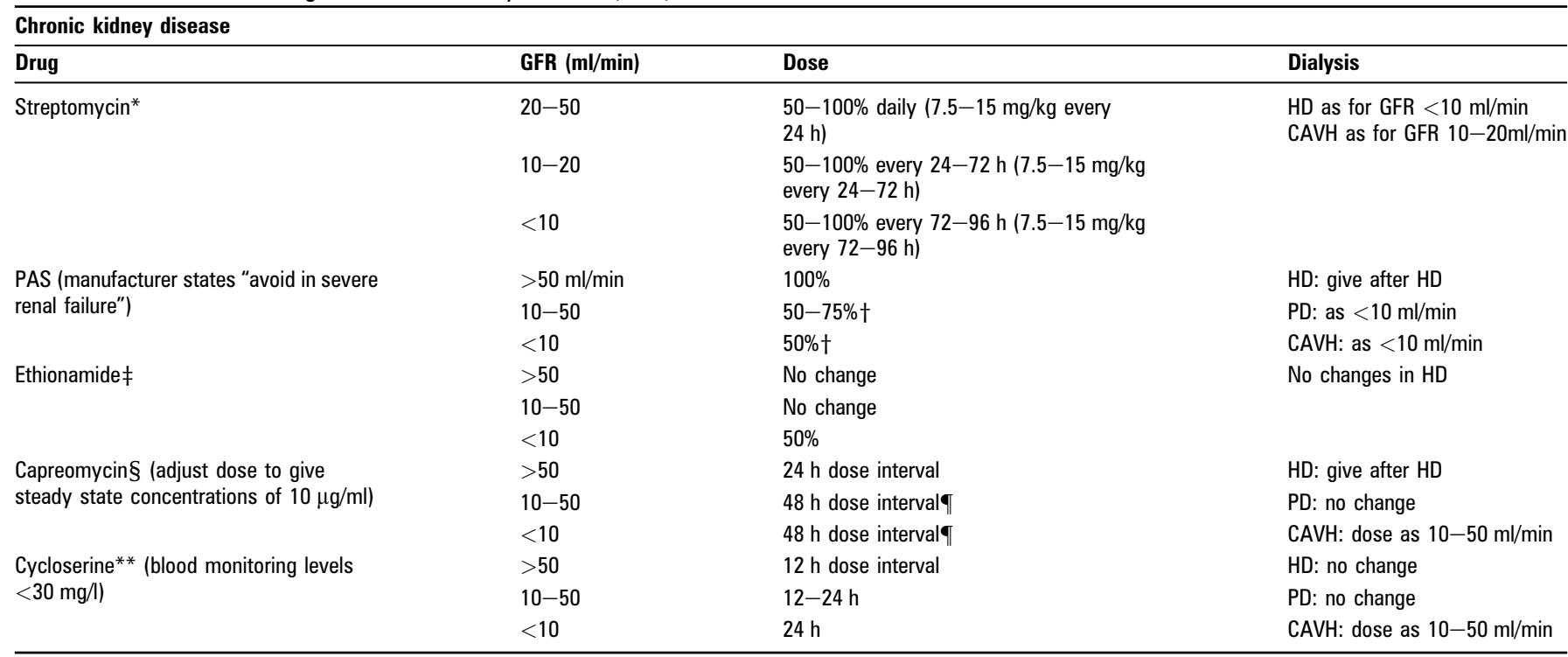

*Intramuscular: $15 \mathrm{mg} / \mathrm{kg}$ (max $1 \mathrm{~g}$ daily). Dose is reduced in $<50 \mathrm{~kg}$ and $>40$ years to max $500-750 \mathrm{mg}$ daily or $12-15 \mathrm{mg} / \mathrm{kg} 2-3$ times/week. Peak plasma concentrations of streptomycin should be between 15 and $40 \mu \mathrm{g} / \mathrm{ml}$ and trough concentrations $<3-5 \mu \mathrm{g} / \mathrm{ml}$ or $<1 \mu \mathrm{g} / \mathrm{ml}$ in CKD or those $>50$ years.

tCaution when reducing dose of PAS (may become subtherapeutic). Usual adult dose $4 \mathrm{~g}$ three times a day. ATS recommend $4 \mathrm{~g}$ twice daily if creatinine clearance $<30 \mathrm{ml} / \mathrm{min}$. Granules should be administered in acidic food or drink with a $\mathrm{pH}<5$ (eg, fruit juice) and should be swallowed without chewing.

‡Adults $15-20 \mathrm{mg} / \mathrm{kg} /$ day in single or divided doses (usual dose $500 \mathrm{mg}-1 \mathrm{~g}$ daily). ATS recommend $250-500 \mathrm{mg}$ daily.

§Adults $1 \mathrm{~g}$ intramuscular every $24 \mathrm{~h}$ (not to exceed $20 \mathrm{mg} / \mathrm{kg} /$ day) 9 or 3 times/week. Do therapeutic drug monitoring.

**Usual adult dose $500 \mathrm{mg}-1 \mathrm{~g}$ daily in divided doses, monitored by therapeutic drug monitoring. The initial adult dosage most frequently given is $250 \mathrm{mg}$ twice daily at $12 \mathrm{~h}$ intervals for the

first 2 weeks. In severe CKD, $500 \mathrm{mg} 3$ times/week. A daily dosage of $1 \mathrm{~g}$ should not be exceeded. Careful monitoring for evidence of neurotoxicity.

CAVH, continuous arteriovenous haemodialysis; GFR, glomerular filtration rate; HD, haemodialysis; PAS, para-amino salicylic acid; PD, peritoneal dialysis. 